\title{
The Landscape of Portraits
}

\author{
Christopher Morgan
}

I Ingraham explains that, "As a subject, the line must be outlined - given a shape or character - and it is precisely at the moment when the line takes a shape that it eludes our grasp." (1996:67)
Fig. 1 Iron Man, 2008. Acrylic on canvas, $1200 \times 1500 \mathrm{~mm}$.

Fig. 2 Secure Hord, 2008. Acrylic on canvas, $1220 \times 1830 \mathrm{~mm}$.

This series of four drawings, located in the expanded field of painting, explores the indeterminate relationship between the structure/frame and picture plane. This enquiry looks to understand new operations between the two by exploring Gilles Deleuze and Félix Guattari's idea of faciality through the manipulation of framing and the multiplication of surface planes. In doing so, these drawings have implications for architecture.

The first drawing of this series, Iron Man (Fig. 1), opens this enquiry with a black lattice type line that configures the torch beam (the work's dominant visual frame) as integral to the painted surface. The line also has the ability to see through the painting: the torch as x-ray through the work (and world) and its operational frames.Catherine Ingraham explains that it is impossible to know the world outside of its representations due to the "ever-present structure of the frame, the lens, the world, the apparatuses of representation" (1996: 65). Herein lies the problematic: as the configuration of the frame in Iron Man does not organise the world in the Cartesian sense, its relation to the picture plane is problematised.

The faciality and, in particular, the face-landscape relations discussed by Deleuze and Guattari, provide an understanding of the possible operations occurring between the picture plane and the frame. In these drawings, the lines of the face are not Ingraham's line but something much closer to Deleuze and Guattari's line of identity, which paradoxically deterritorialises.

Although a literal face is represented in Secure Hord and Make it Now (Figs. 2 and 3), their appearances show how the face is (literally) transformed into a field or a milieu on which signification and subjectification can take place. In these two works, "faciality" as a territorialising and deterritorialising procedure, emerges at a certain point in the drawing's history (on the eve of a "finished" work) when the line as frame is at risk of disappearing. ${ }^{1}$

Fig. 1

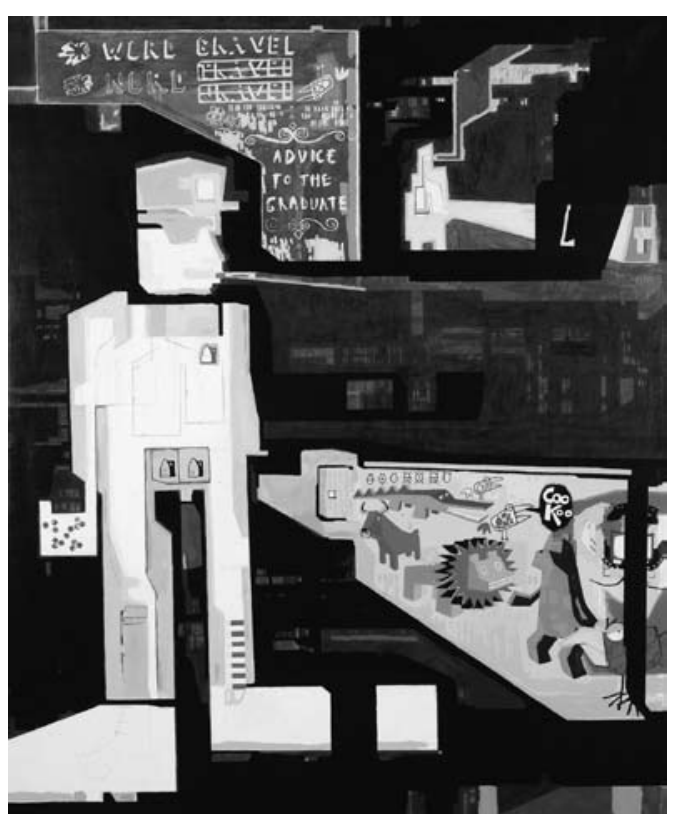

Fig. 2

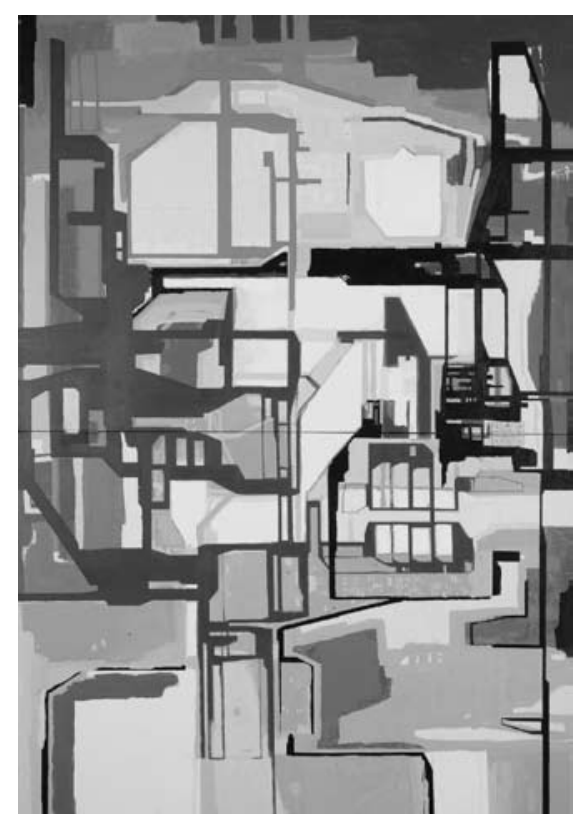




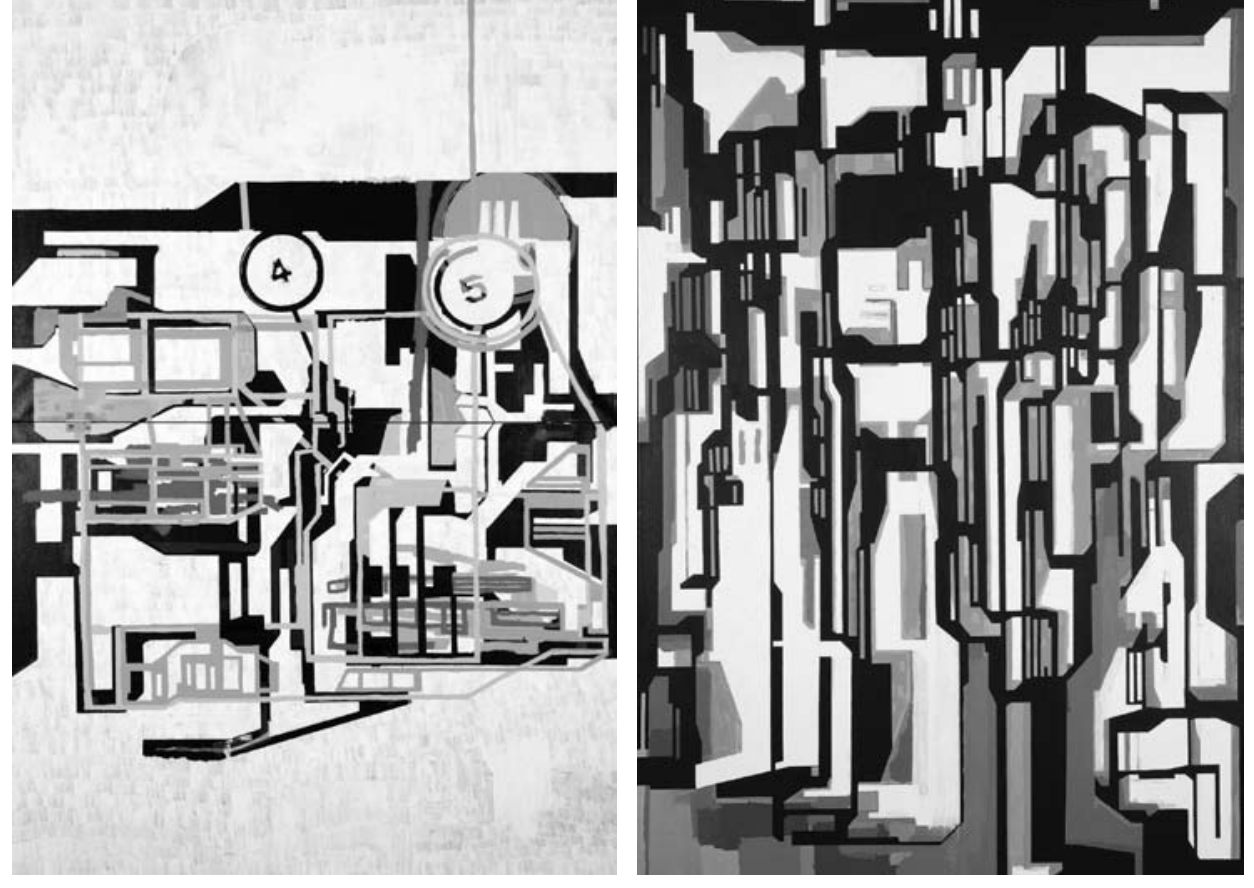

Fig. 3

Fig. 4
The last work in this series, One-Eyed Jacks (Fig. 4), acknowledges this idea of faciality from its inception. The figure (a spaghetti western bandito) engulfs the picture plane, already questioning its content before being transformed by reframing. Deleuze and Guattari speak of the transformational workings of this system: "This machine is called the faciality machine because it is the social production of face, because it performs the facialization of the entire body and all its surroundings and objects, and the landscapification of all worlds and milieus" (1987: 181). Deleuze and Guattari advocate a challenge to the anthropological machine by reterritorialising faciality through deterritorialising the body (174). ${ }^{2}$

How the drawn face (portrait) and landscape reterritorialise each other offers a place for the indeterminacy created by these works to allow the prop/frame and the content/plane to play out a new order. The deterritorialised face is the white wall, a plane empty of content or identity. The prop/frame, which refuses to have a static relationship with the picture plane, can now inscribe meaning, and therefore operates as a landscape (field of relations). On the deterritorialised face, the drawn line reconceptualises identity in architecture: no longer does the facade in architecture provide identity through a static coherence, but as a landscape of continuously moving features with no exacting relations.

What these drawings do is challenge the hegemony of the plan and the notion of form as the only means of providing a sense of the architectural. The drawn line, while allowing this idea of identity to occur, also allows the dispersal of meaning and thus the continual reterritorialisation on the deterritorialised face. This transfigures the face (face as line) to become a subject maker. ${ }^{3}$ When we are confronted by a face - as in these drawings - whether reflective or intensive, we re-coordinate our vision of the world and consequently our actions in that world, to approach the world anew.

\section{References}

Deleuze, D. \& Guattari, F. (1987). A Thousand Plateaus: Capitalism and Schizophrenia. (B. Massumi, Trans.). Minneapolis: University of Minnesota Press.

Ingraham, C. (1996). Lines and Linearity: Problems in Architectural Theory. In A. Kahn (Ed.), Drawing/Building/Text (63-84). New Jersey: Princeton Architectural Press.
Fig. 3 Make It Now, 2008. Acrylic on canvas, $1210 \times 1820 \mathrm{~mm}$.

Fig. 4 One-Eyed Jacks, 2008. Acrylic on canvas, $1200 \times 1800 \mathrm{~mm}$.

2 Deleuze and Guattari give an ex ample of this face-landscape relation: "Architecture positions its ensembles houses, towns or cities, monuments or factories - to function like faces in the landscape they transform." (1987: 172)

3 For an example of the relationship between faciality, subjectivity and architecture see Loo, S. (2009). The Transverse Face: Architecture X Culture. In Gatley, J. (Ed.), Cultural Crossroads: Proceed ings of the 26th International SAHANZ Conference. The University of Auckland, New Zealand, 2-5 July 2009). Auckland: SAHANZ. 
Invited Papers 